Fifth International Conference on Sustainable Construction Materials and

Technologies. http://www.claisse.info/Proceedings.htm

\title{
AN EVALUATION ON ANTI-CORROSION PERFORMANCE OF GALVANIZED (ZINC-COATED) REBAR IN CONCRETE BY GALVANOSTATIC TECHNIQUE
}

\author{
Hongbok-Choe $^{1}$, Yuhei Nishio ${ }^{2}$, and Manabu Kanematsu ${ }^{3}$
}

${ }^{1} 4^{\text {th }}$ Floor, Building No.2, 2641, Yamazaki, Noda-shi, Chiba, 278-0022, Japan, hongbokchoe@gmail.com, Department of Architecture, Graduate School of Science and Technology, Tokyo University of Science.

${ }^{2} 4^{\text {th }}$ Floor, Building No.2, 2641, Yamazaki, Noda-shi, Chiba, 278-0022, Japan, y.nishio@rs.tus.ac.jp, Department of Architecture, Faculty of Science and Technology, Tokyo University of Science.

${ }^{3} 4^{\text {th }}$ Floor, Building No.2, 2641, Yamazaki, Noda-shi, Chiba, 278-0022, Japan, manabu@rs.noda.tus.ac.jp, Department of Architecture, Faculty of Science and Technology, Tokyo University of Science.

\begin{abstract}
Galvanized rebar is known to perform an anti-corrosion effect by sacrificial anodic reaction of zinc. Meanwhile, accelerated corrosion test by galvanostatic method has been used to evaluate corrosion and/or anti-corrosion property of the rebar in concrete. However, in using this test on galvanized rebar, the influence of applied current density has not yet been clarified. In this study, to investigate adequate test condition, various range of applied current density, which is $20 \sim 230 \mu \mathrm{A} / \mathrm{cm}^{2}$, was tested on galvanized rebar embedded in concrete. As a result, galvanized rebar was found to perform the increase of polarization resistance $\left(R_{p}\right)$ as the applied current density is lower. Furthermore, $R_{p}$ showed the increasing behavior as corrosion has progressed. Moreover, the actual corrosion amount was shown smaller than the designed one by performing adequate anti-corrosion behavior. In conclusion, within $160 \mu \mathrm{A} / \mathrm{cm}^{2}$ was assumed to be appropriate in the scope of this study.
\end{abstract}

Keywords: Corrosion, galvanized rebar, concrete.

\section{INTRODUCTION}

Recently, studies which evaluate anti-corrosion performance of galvanized rebar have been actively carried out. Specifically, corrosion behavior in different corrosive environment has been under investigation (Choe et al. (2018a, 2018b), Niwa et al. (2017), Kouril et al. (2017), Figueira et al. (2014), Sistonen (2009), Farina and Duffo (2007), Yeomans (2004), Andrade and Alonse (2004)). Galvanized rebar is known to perform an anti-corrosion effect by sacrificial anodic reaction of zinc. When it is 
embedded in concrete, whether there is damaged surface or not, zinc coating corrodes itself until its dissolution is finished replacing for steel substrate. Therefore, galvanized rebar (hereafter, HDZ bar) has been expected to show long-term corrosion protection service life (Yeomans, 2004). Meanwhile, to evaluate corrosion and/or anti-corrosion property of the rebar in concrete, accelerated corrosion test by galvanostatic method has been utilized in Japan (Takaya et al., 2013). This test simulates the principal of electrolytic corrosion of anode metal by using external DC power supply and nobler metal (hereafter, EC test). It is able to generate and maintain a controlled anodic reaction of HDZ bar with constant direct current. Thus, it is effective method in evaluating HDZ bar's corrosion amount quantitatively, by means of test period and integrated current amount. However, because most of studies by EC test have been mainly focused on ordinary rebar, as a purpose to break passivation layer, the applied current density (hereafter, AC density) had to be severe, such as in the range of $100 \sim 1500 \mu \mathrm{A} / \mathrm{cm}^{2}$ (Takaya et al., 2013). On the other hand, applicability of this test on HDZ bar has not been fully clarified yet. The reason is that there is a concern on deciding appropriate range of AC density. Because HDZ bar is protected by intentional anodic reaction of zinc, if it is tested under strong $\mathrm{AC}$ density as same as ordinary rebar, the corrosion rate of zinc would be abnormally fast which makes it unable to function as anti-corrosive film. If so, EC test would be unsuitable method for the prediction of HDZ bar's service life in actual environment.

In this study, to investigate adequate $\mathrm{EC}$ test condition, various range of $\mathrm{AC}$ density, which is $20 \sim 230 \mu \mathrm{A} / \mathrm{cm}^{2}$ that is comparatively in the lower range than previous studies, was tested on HDZ bar embedded in concrete. In addition, different $\mathrm{W} / \mathrm{C}$ and test period were considered. After EC test, electrochemical test that is able to evaluate polarization resistance and corrosion rate was conducted. Finally, evaluation on actually corroded amount of zinc by testing period and XRD analysis was carried out.

\section{EXPERIMENTAL}

\section{Scope of the Study}

Table 1 and 2 indicates specimen list which includes the scope of the study. In this study, water/cement ratio of concrete (W/C), applied current density from DC power supply (AC density) and designed corrosion amount (hereafter, DCA) was considered as variables for the experiment.

Firstly, two types of concretes were prepared to have $50 \%$ and $83.5 \%$ of W/C, which are normal and high-water content condition. It is to compare with whether there is an influence by physical property of concrete while corrosion of HDZ bar is in progress. Table 3 indicates their composition and properties. Secondly, AC density was planned with different extents. 160,80 and $20 \mu \mathrm{A} / \mathrm{cm}^{2}$ were applied on W/C50\% concrete. In terms of $\mathrm{W} / \mathrm{C} 83.5 \%$ concrete, 230 and $80 \mu \mathrm{A} / \mathrm{cm}^{2}$ were applied. Between them, $80 \mu \mathrm{A} / \mathrm{cm}^{2}$ was set up as identical corrosion condition. Meanwhile, DC power supply which was used in this study was able to adjust its minimum current amount up to $0.01 \mathrm{~A}(=10000 \mu \mathrm{A})$. Thus, $0.01 \mathrm{~A}$ was fixed to provide the lowest corrosion current on all specimens. Instead, surface area of HDZ bar $\left(\mathrm{cm}^{2}\right)$ was adjusted on each specimen 
in satisfying $\mathrm{AC}$ density $\left(\mu \mathrm{A} / \mathrm{cm}^{2}\right)$.

Table 1. Specimen List

\begin{tabular}{|c|c|c|c|c|}
\hline No & Specimen & $\begin{array}{l}\mathrm{W} / \mathrm{C} \\
(\%)\end{array}$ & $\begin{array}{l}\text { Applied current } \\
\text { density }\left(\mu \mathrm{A} / \mathrm{cm}^{2}\right)\end{array}$ & $\begin{array}{c}\text { Surface area of } \\
\text { specimen rebar }\left(\mathrm{cm}^{2}\right)\end{array}$ \\
\hline 1 & W50-D160 & \multirow{3}{*}{50} & 160 & 62.5 \\
\hline 2 & W50-D80 & & 80 & 125 \\
\hline 3 & W50-D20 & & 20 & 500 \\
\hline 4 & W83.5-D80 & \multirow{3}{*}{83.5} & 80 & 125 \\
\hline $5^{1}$ & W83.5-D230(1) & & 230 & \multirow{2}{*}{43.5} \\
\hline $6^{1}$ & W83.5-D230(2) & & 230 & \\
\hline
\end{tabular}

${ }^{1}$ Specimen No.5 and 6 are identical.

Thirdly, DCA (\%) indicates predicted corrosion amount of zinc coating as EC test period is progressed. From the measured zinc thickness of HDZ bar which was not corroded in the initial stage, $180 \mu \mathrm{m}$ was decided as $100 \%$ of DCA. Thickness meter was used and over 10 points was randomly chosen on the surface of HDZ bar. In this study, to compare with actual and designed corrosion amount, single specimen was prepared to be corroded within $10 \sim 100 \%$ of DCA. Therefore, 21 specimens were used for EC test. EC test period (h), which corresponds to DCA, was decided based on faraday's law (ASTM G102-89(2015)e1). This law explains the co-relation of corrosion current density $\left(i_{\text {corr }}, \mu \mathrm{A} / \mathrm{cm}^{2}\right)$ and corrosion rate $(C R, \mu \mathrm{m} /$ year $)$. By this law, $C R$ of zinc is expressed as $14.98\left[\mu \mathrm{m} /\right.$ year] when $i_{\text {corr }}$ is $1\left[\mu \mathrm{A} / \mathrm{cm}^{2}\right]$ (Sistonen, 2009). Accordingly, for example, when AC density is $160\left[\mu \mathrm{A} / \mathrm{cm}^{2}\right]$, it can be expressed as $(160 \times 14.98)\left[\mu \mathrm{m} /\right.$ year] . This means it takes $(160 \times 14.98)^{-1}$ [year] to corrode $1 \mu \mathrm{m}$ of zinc. Thus, to corrode $180 \mu \mathrm{m}$ of zinc $\left(100 \%\right.$ of DCA), it needs $\left\{180 \times(160 \times 14.98)^{-1}\right\}$ [year]. In Table 2, [year] was converted into hour [h]. By this manner, EC test period was calculated on all specimens.

Table 2. Specimen List (continued)

\begin{tabular}{|c|c|c|c|c|}
\hline No & Specimen & $\begin{array}{l}\text { Designed } \\
\text { corrosion } \\
\text { amount }(\%)\end{array}$ & $\begin{array}{l}\text { Predicted corrosion } \\
\text { thickness of zinc } \\
(\mu \mathrm{m})\end{array}$ & $\begin{array}{c}\text { EC test period }[\mathrm{h}] \\
\text { (integrated current } \\
\text { amount }\left[\mathrm{mA} \times \mathrm{h} / \mathrm{cm}^{2}\right] \text { ) }\end{array}$ \\
\hline \multirow{4}{*}{1} & \multirow{4}{*}{ W50-D160 } & 25 & 45 & $162.2(26.0)$ \\
\hline & & 50 & 90 & $324.5(51.9)$ \\
\hline & & 75 & 135 & $486.7(77.9)$ \\
\hline & & 100 & 180 & $649.0(103.8)$ \\
\hline \multirow{4}{*}{2} & \multirow{4}{*}{ W50-D80 } & 25 & 45 & $324.5(26.0)$ \\
\hline & & 50 & 90 & $649.0(51.9)$ \\
\hline & & 75 & 135 & $973.2(77.9)$ \\
\hline & & 100 & 180 & $1297.7(103.8)$ \\
\hline \multirow{2}{*}{3} & \multirow{2}{*}{ W50-D20 } & 25 & 45 & $1297.7(26.0)$ \\
\hline & & 50 & 90 & $2595.4(51.9)$ \\
\hline \multirow{4}{*}{4} & \multirow{4}{*}{ W83.5-D80 } & 15 & 27 & $195.0(15.6)$ \\
\hline & & 25 & 45 & $324.5(26.0)$ \\
\hline & & 50 & 90 & $649.0(51.9)$ \\
\hline & & 100 & 180 & $1297.7(103.8)$ \\
\hline
\end{tabular}




\begin{tabular}{|c|c|c|c|c|}
\hline \multirow{4}{*}{5} & 10 & 18 & $45.2(10.4)$ \\
\cline { 3 - 5 } & \multirow{3}{*}{ W83.5-D230(1) } & 25 & 45 & $113.0(26.0)$ \\
\cline { 3 - 5 } & & 50 & 90 & $225.7(51.9)$ \\
\cline { 3 - 5 } & & 75 & 135 & $338.7(77.9)$ \\
\cline { 3 - 5 } & & 100 & 180 & $451.3(103.8)$ \\
\hline \multirow{3}{*}{6} & \multirow{3}{*}{ W83.5-D230(2) } & 25 & 45 & $113.0(26.0)$ \\
\cline { 3 - 5 } & & 50 & 90 & $225.7(51.9)$ \\
\cline { 3 - 5 } & & 75 & 135 & $338.7(77.9)$ \\
\hline
\end{tabular}

Table 3. Composition of Concrete for Specimen

\begin{tabular}{|c|c|c|c|c|c|c|c|c|c|}
\hline \multirow{2}{*}{$\begin{array}{l}\text { W/C } \\
(\%)\end{array}$} & \multicolumn{5}{|c|}{ Unit weight $\left(\mathrm{kg} / \mathrm{cm}^{3}\right)$} & \multirow{2}{*}{$\begin{array}{l}\text { Air } \\
(\%)\end{array}$} & \multirow{2}{*}{$\begin{array}{l}\text { Slump } \\
(\mathrm{cm})\end{array}$} & \multirow{2}{*}{$\begin{array}{l}\text { Flow } \\
(\mathrm{cm})\end{array}$} & \multirow{2}{*}{$\begin{array}{c}\mathrm{CS}^{4} \\
\left(\mathrm{~N} / \mathrm{mm}^{2}\right)\end{array}$} \\
\hline & $\mathrm{W}$ & $\mathrm{C}$ & $\mathrm{S}^{1}$ & $\mathrm{G}^{2}$ & $\mathrm{Ad}^{3}$ & & & & \\
\hline 50 & 185 & 370 & 795.72 & 942.84 & 1.85 & 3 & 18.9 & 32 & 32.4 \\
\hline 83.5 & 193 & 232 & 947 & 857 & 2.32 & 4.1 & 19.5 & 34 & 21.8 \\
\hline
\end{tabular}

${ }^{1}$ Fine aggregate; ${ }^{2}$ Coarse aggregate; ${ }^{3}$ Admixture: ${ }^{4}$ Compressive strength at 28 days

\section{Preparation of Specimen}

Fig.1 shows specimen setup. The HDZ bar used in the experiment had D16 diameter and deformed shape. Concrete was made to have $100 \times 100 \mathrm{~mm}$ of cross section and the length was decided by AC density on each specimen. For example, it was decided that $62.5 \mathrm{~cm}^{2}$ is needed to satisfy $160 \mu \mathrm{A} / \mathrm{cm}^{2}$ of AC density. Because a single rebar was embedded in concrete, the length $(l)$ was calculated as $l=62.5 \times(\pi \times d)^{-1} . d$ is diameter of HDZ bar. On the cross section, electric wire was connected with HDZ bar on one side, which is to make HDZ bar as anode in EC test. After that, insulation by epoxy adhesive was conducted on both side.

\section{Accelerated Corrosion Test by Galvanostatic Method (EC test)}

Fig.2 explains composition of EC test. Firstly, inside the container, stainless steel plate was used as cathode and placed on the bottom. After that, the specimen was sunken into tap water with having a distance from the plate. Secondly, by means of DC power supply, specimen was connected to $(+)$ terminal as anode and stainless steel plate was connected to $(-)$ terminal as cathode. Finally, by turning on the device with having the applying current amount fixed (0.01A), EC test was initiated. While the test is in progress, tap water was periodically supplied into the container to fully wet the specimen. After the test, on HDZ bar, polarization test and the measurement of remained coating thickness was carried out.

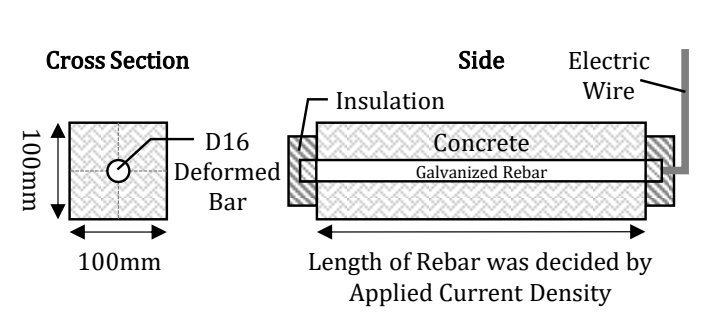

Fig.1 Specimen Preparation

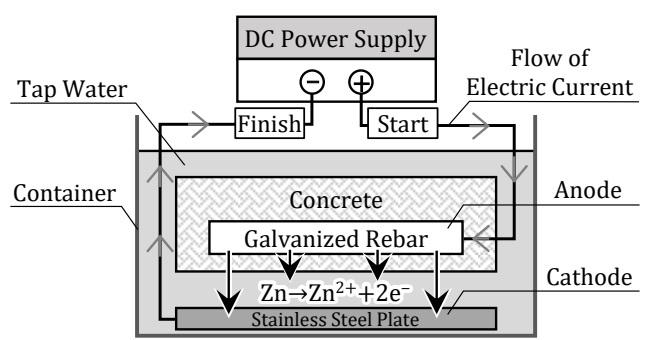

Fig.2 EC Test 


\section{Polarization test}

Fig.3 shows outline of polarization test. By means of potentiostatic technique, three electrodes were used which are $\mathrm{Ag} / \mathrm{AgCl}$ electrode (reference), $\mathrm{HDZ}$ bar in the specimen (working) and stainless steel plate (counter). As a test condition, scanning rate of potential was $1 \mathrm{mV} / \mathrm{s}$, anodic polarization range was $E_{\text {corr }}+250 \mathrm{mV}$ and cathodic polarization range was $E_{\text {corr }}-250 \mathrm{mV}$. $E_{\text {corr }}$ is a corrosion potential which was measured just prior to polarization. After the test, based on stern-geary equation as shown in (1), electrochemical properties were evaluated (ASTM G102-89(2015)e1). From the measured potential (E) - current (I) graph, tafel constant $(B)$ and polarization resistance $\left(R_{p}\right)$ was obtained (Poursaee (2010), Badea et al. (2010)).

$i_{\text {corr }}=B \times R_{p}^{-1}=\left\{\left(\beta_{a} \times \beta_{c}\right) / 2.3 \times\left(\beta_{a}+\beta_{c}\right)\right\} \times R_{p}^{-1}$

$i_{\text {corr }}$ : Corrosion current density $\left(\mu \mathrm{A} / \mathrm{cm}^{2}\right), B$ : Tafel constant $(\mathrm{V}), R_{p}:$ Polarization resistance $\left(\Omega \times \mathrm{cm}^{2}\right), \beta_{a}$ : Anodic gradient (V/decade), $\beta_{c}$ : Cathodic gradient (V/decade)

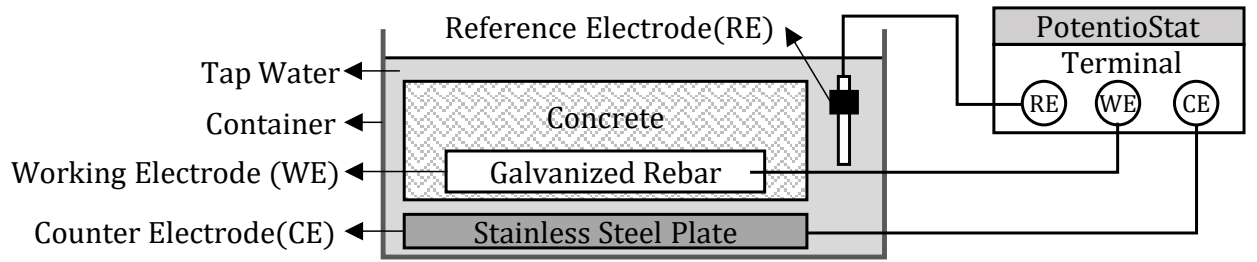

Fig.3 Polarization Test

\section{Measurement of Remained Coating Thickness}

Fig.4 indicates the process of measuring remained coating thickness in order to evaluate actual corrosion amount of zinc. After taking out HDZ bar from the concrete, weight measurement and treatment of zinc coating was conducted in accordance with JIS H 0401: 2013 (ISO 1460: 1992 is corresponded). Following the standard, corrosion amount was expressed as remained coating thickness which is shown in Equation (2).

$t=\left\{\left(\mathrm{W}_{1}-\mathrm{W}_{2}\right) / 7.2 \mathrm{~S}\right\} \times 10^{6}$

$t$ : Remained thickness of zinc coating $(\mu \mathrm{m}), \mathrm{W}_{1}$ : Weight of HDZ bar before elimination of zinc coating $(\mathrm{g}), \mathrm{W}_{2}$ : Weight of $\mathrm{HDZ}$ bar after elimination of zinc coating $(\mathrm{g}), 7.2$ : Density of zinc $\left(\mathrm{g} / \mathrm{m}^{3}\right), \mathrm{S}$ : Surface area of the rebar $\left(\mathrm{mm}^{2}\right)$

Cross Section

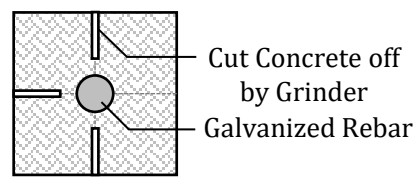

(1) Concrete cutting

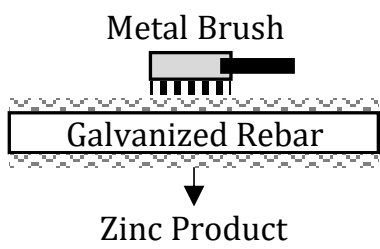

[Measurement of $\left.\mathrm{W}_{1}\right]$

(2) Removal of zinc corrosion product
$\mathrm{HCl} 500 \mathrm{ml}+$ Distilled Water

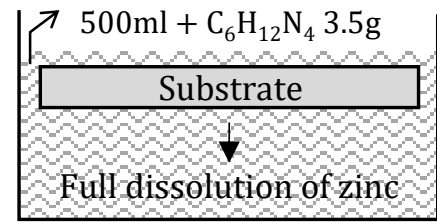

[Measurement of $\left.\mathrm{W}_{2}\right]$

(3) Elimination of zinc coating on substrate

Fig.4 Specimen Treatment for Measuring Remained Coating Thickness 


\section{RESULT AND DISCUSSION}

Table 4 indicates electrochemical properties of all specimens. It was shown that there has been gradual change by the progress of DCA. In this study, $R_{p}$ was mainly discussed to clarify HDZ bar's corrosion behavior. Table 5 indicates evaluated corrosion amount of zinc on all specimens. By means of Equation (2), remained coating thickness (RCT) and thickness change after EC was calculated. On the thickness change, $\mathrm{W}_{1}$ is presumed weight of not-corroded HDZ bar by its length $(=1.56 \mathrm{~g} / \mathrm{mm}), \mathrm{W}_{2}$ is weight of HDZ bar before elimination of zing coating.

Prior to discuss the experiment result by progress of DCA, it was shown that some data was found scattered from general tendency of specimen's corrosion behavior. This result was due to an influence that all specimens were individually tested. Although specimens were prepared in the same condition, it was presumed that there was partially non-uniform accelerated corrosion during the EC test. For this reason, Fig.6 10 presented the test results which showed reliable tendency.

Table 4. Electrochemical Properties of Specimens after EC Test

\begin{tabular}{|c|c|c|c|c|c|}
\hline No & Specimen & $\operatorname{DCA}^{1}(\%)$ & $E_{\text {corr }}^{2}(\mathrm{~V})$ & $R_{p}{ }^{3}\left(\mathrm{~K} \Omega \cdot \mathrm{cm}^{2}\right)$ & $i_{\text {corr }}{ }^{4}\left(\mu \mathrm{A} / \mathrm{cm}^{2}\right)$ \\
\hline \multirow{4}{*}{1} & \multirow{4}{*}{ W50-D160 } & 25 & -0.830 & 11.8 & 5.3 \\
\hline & & 50 & -0.963 & 13.5 & 4.7 \\
\hline & & 75 & -0.707 & 18.8 & 3.3 \\
\hline & & 100 & -0.590 & 27.5 & 2.3 \\
\hline \multirow{4}{*}{2} & \multirow{4}{*}{ W50-D80 } & 25 & -0.916 & 27.2 & 2.3 \\
\hline & & 50 & -0.810 & 41.9 & 1.5 \\
\hline & & 75 & -0.833 & 125.8 & 0.5 \\
\hline & & 100 & -0.957 & 77.3 & 0.8 \\
\hline \multirow{2}{*}{3} & \multirow{2}{*}{ W50-D20 } & 25 & -0.489 & 53.8 & 1.2 \\
\hline & & 50 & -0.397 & 69.5 & 0.9 \\
\hline \multirow{4}{*}{4} & \multirow{4}{*}{ W83.5-D80 } & 15 & -0.882 & 19.63 & 2.87 \\
\hline & & 25 & -0.931 & 23.26 & 2.42 \\
\hline & & 50 & -0.644 & 56.81 & 0.99 \\
\hline & & 100 & -0.549 & 69.13 & 0.81 \\
\hline \multirow{5}{*}{5} & \multirow{5}{*}{ W83.5-D230 (1) } & 10 & -0.463 & 10.20 & 5.52 \\
\hline & & 25 & -0.901 & 14.66 & 3.84 \\
\hline & & 50 & -0.960 & 26.23 & 2.15 \\
\hline & & 75 & -0.879 & 20.06 & 2.81 \\
\hline & & 100 & -0.758 & 6.23 & 9.04 \\
\hline \multirow{3}{*}{6} & \multirow{3}{*}{ W83.5-D230 (2) } & 20 & -0.957 & 15.54 & 3.62 \\
\hline & & 50 & -0.813 & 21.66 & 2.60 \\
\hline & & 75 & -0.884 & 158.0 & 0.36 \\
\hline
\end{tabular}

${ }^{1}$ Designed corrosion amount; ${ }^{2}$ Corrosion potential; ${ }^{3}$ Polarization resistance; ${ }^{4}$ Corrosion current density and it was calculated from average tafel constant which was $0.063 \mathrm{~V}$ (W/C50\% specimens) and $0.056 \mathrm{~V}$ (W/C83.5\% specimens) 
Table 5. Evaluation of Corroded Amount of Specimens after EC Test

\begin{tabular}{|c|c|c|c|c|c|}
\hline No & Specimen & $\begin{array}{l}\text { DCA } \\
(\%)\end{array}$ & $\begin{array}{l}\mathrm{RCT}^{1} \\
(\mu \mathrm{m})\end{array}$ & $\begin{array}{l}\text { Thickness change } \\
\text { after EC test }{ }^{2}(\mu \mathrm{m})\end{array}$ & $\begin{array}{l}\text { Cracks on } \\
\text { concrete }^{3}\end{array}$ \\
\hline \multirow{4}{*}{1} & \multirow{4}{*}{ W50-D160 } & 25 & 203.70 & -54.29 & \multirow{10}{*}{ Unfound } \\
\hline & & 50 & 188.37 & -50.03 & \\
\hline & & 75 & 180.26 & -36.09 & \\
\hline & & 100 & 159.11 & -6.27 & \\
\hline \multirow{4}{*}{2} & \multirow{4}{*}{ W50-D80 } & 25 & 180.10 & -40.33 & \\
\hline & & 50 & 178.12 & -52.92 & \\
\hline & & 75 & 188.77 & -55.62 & \\
\hline & & 100 & 154.84 & -16.12 & \\
\hline \multirow{2}{*}{3} & \multirow{2}{*}{ W50-D20 } & 25 & 187.16 & -48.30 & \\
\hline & & 50 & 170.08 & -34.06 & \\
\hline \multirow{4}{*}{4} & \multirow{4}{*}{ W83.5-D80 } & 15 & 123.60 & 23.31 & \multirow{2}{*}{ Unfound } \\
\hline & & 25 & 111.43 & 37.40 & \\
\hline & & 50 & 89.95 & 70.05 & Found \\
\hline & & 100 & 97.63 & 79.07 & Found \\
\hline \multirow{5}{*}{5} & \multirow{5}{*}{ W83.5-D230 (1) } & 10 & & t-measured & \multirow{2}{*}{ Unfound } \\
\hline & & 25 & 134.78 & 20.29 & \\
\hline & & 50 & 115.32 & 43.74 & Found \\
\hline & & 75 & 98.56 & 82.81 & Found \\
\hline & & 100 & 102.95 & 79.90 & Found \\
\hline \multirow{3}{*}{6} & \multirow{3}{*}{ W83.5-D230 (2) } & 20 & 118.94 & 7.11 & \multirow{3}{*}{ Unfound } \\
\hline & & 50 & 132.85 & -0.73 & \\
\hline & & 75 & 101.00 & 52.44 & \\
\hline
\end{tabular}

${ }^{1}$ Remained coating thickness; ${ }^{2}$ [Presumed weight of not-corroded HDZ bar $\left.\left(\mathrm{W}_{1}\right)\right]-$ [Measured weight of corroded HDZ bar $\left(\mathrm{W}_{2}\right)$ ]. (-) indicates increase of thickness; ${ }^{3} \mathrm{~A}$ crack which was formed longitudinally with rebar and broke concrete

\section{Surface of Galvanized Rebar by EC Test Period}

Fig. 5 shows surface of HDZ bar which corroded by EC test at $80 \mu \mathrm{A} / \mathrm{cm}^{2}$ of AC density. This result was found identically on other specimens which were tested at different AC density. Specimens which were embedded in W/C50\% (left) and W/C83.5\% (right) were compared. This comparison was carried out in Fig.6, 7 and 10 as well. On each surface of HDZ rebar in Fig.5, both sides (top and bottom) were observed.

In $\mathrm{W} / \mathrm{C} 50 \%$, black-colored film, which was presumed as oxide film, was formed over entire surface of rebar from the stage of short-term corrosion (DCA: 25\%). It was maintained stable until $100 \%$ of DCA. In addition, only one side of rebar was filled with zinc product presuming that it occurred after the formation of oxide film. Powers and Breiter (1969) found that gray is $\mathrm{ZnO}$ and white is $\mathrm{Zn}(\mathrm{OH})_{2}$. Moreover, a gentle increase of the product was shown as DCA was progressed. Nevertheless, no corrosion of substrate was found. Originally, the formation of oxide film is not by corrosion of zinc. However, in the process of manufacturing HDZ bar, some other components are included to secure stable structure of zinc coating on the substrate (Langill and Dugan, 2004). In this experiment, from the observation of cross section, it was found that the oxide film protected the zinc coating such as thin layer. Therefore, it is presumed as a substance which has non-reactive property.

In $\mathrm{W} / \mathrm{C} 83.5 \%$, On the other hand, comparatively dense $\mathrm{Zn}(\mathrm{OH})_{2}$ was formed from the 
early corrosion and it was observed on both sides of the rebar. In addition, corrosion of substrate (red product) was also found on the surface where the thick $\mathrm{Zn}(\mathrm{OH})_{2}$ layer was formed. Though the oxide film was formed, it seemed less stable than the one in $\mathrm{W} / \mathrm{C} 50 \%$. By that reason, it is presumed that corrosion of zinc was actively generated. Therefore, it was clearly shown that high W/C of concrete makes HDZ bar easy to be corroded and generates more $\mathrm{Zn}(\mathrm{OH})_{2}$.

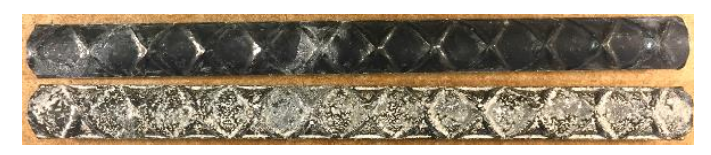

DCA: $25 \%$

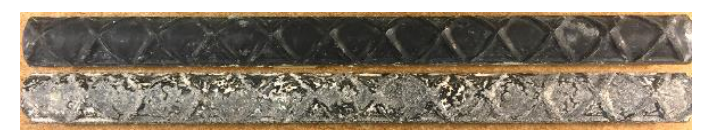

DCA: $50 \%$

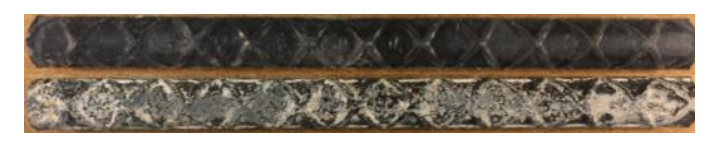

DCA: $75 \%$

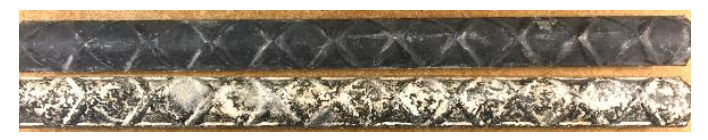

DCA: $100 \%$

$\mathrm{W} / \mathrm{C} 50 \%$

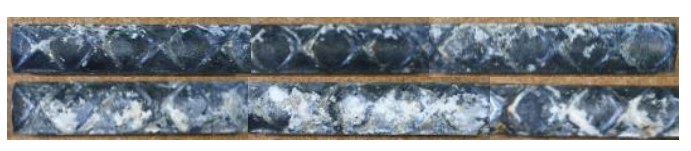

DCA: $15 \%$

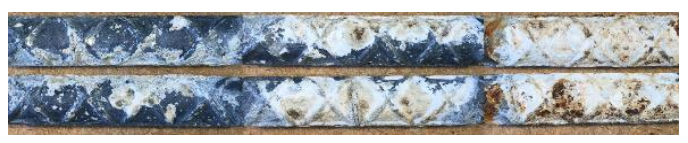

DCA: $25 \%$

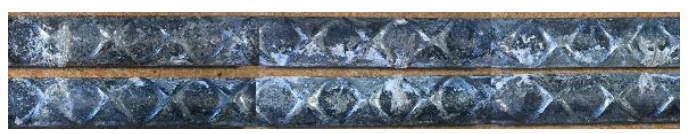

DCA: $50 \%$

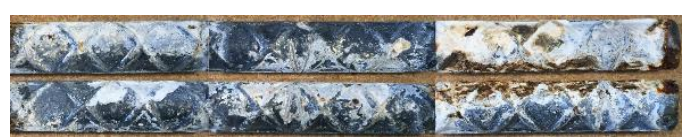

DCA: $100 \%$

$\mathrm{W} / \mathrm{C} 83.5 \%$

Fig. 5 Surface of HDZ Bar by EC Test Period at $80 \mu \mathrm{A} / \mathrm{cm}^{2}$

\section{Electrochemical Properties by Applied Current Density}

Fig.6 indicates behavior of $R_{p}$ on all specimens. In W/C $50 \%$, the behavior was clearly shown with regard to different AC density and progress of DCA. A gradual increase of $R_{p}$ was found and its gradient was generally similar on $25 \%$ interval of test period. This tendency implies that the resistance of oxide film has influenced electrochemical property of HDZ rebar's surface. Although it is difficult to assume whether the corrosion of zinc was suppressed, it seemed that there was no such a radical reaction. By this reason, remained coating thickness was examined to correlate with its $R_{p}$ property. It was also found that higher $\mathrm{AC}$ density caused lower $R_{p}$ when the progressed DCA was same (25\% and $50 \%$ in this experiment). Meanwhile, $R_{p}$ is inversely proportional to $i_{\text {corr }}$. Thus, this tendency shows that AC density is able to influence more accelerated or less reactive corrosion of HDZ bar in spite of identical integrated current amount. Furthermore, it is presumed that the different range of AC density would affect properties of oxide film and zinc product. Therefore, in evaluating anti-corrosion performance of HDZ bar by EC test, it was shown adequate and important to set up low range of AC density to simulate actual corrosion environment closely.

In W/C $83.5 \%$, a gentle increase of $R_{p}$ was shown until $50 \%$ of DCA. In addition, the 
tendency that $R_{p}$ was higher at lower AC density was found as similar as in W/C $50 \%$. However, on the results which DCA were more than $50 \%$, specimens showed remarkable difference compared to the results in W/C50\%. Meanwhile, from the observation of concrete specimen surface, a longitudinal crack which broke half part of cross section was found. This crack was by corrosion of substrate and expansion of the rebar. It happened mostly after $50 \%$ of DCA. By this influence, it is assumed that specimens at $230 \mu \mathrm{A} / \mathrm{cm}^{2}$ showed unstable state of $R_{p}$ such as rapidly steep increase or gentle decrease. In the case of specimen at $80 \mu \mathrm{A} / \mathrm{cm}^{2}$, it showed comparatively steep increase of $R_{p}$ at $50 \%$. However, $R_{p}$ was mostly shown lower in comparison to $\mathrm{W} / \mathrm{C} 50 \%$ due to high W/C of concrete. From this behavior, in the scope of this study, it was found that $230 \mu \mathrm{A} / \mathrm{cm}^{2}$ of AC density accelerates abnormal corrosion progress of zinc and is unsuitable EC test range.

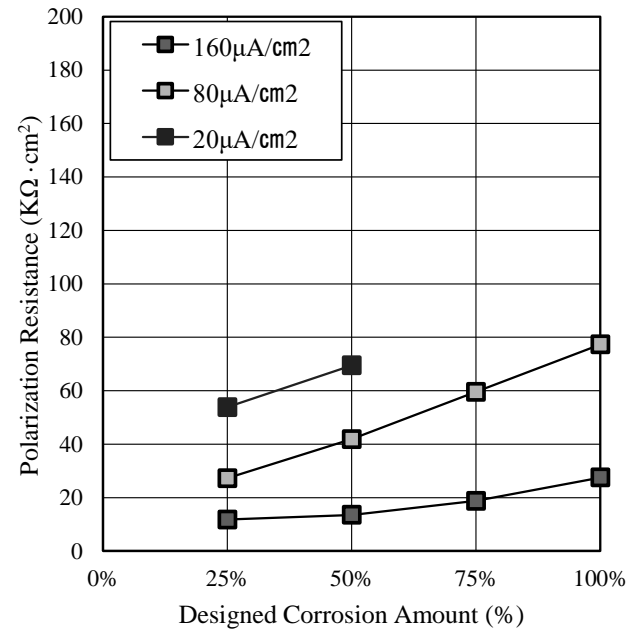

$\mathrm{W} / \mathrm{C} 50 \%$

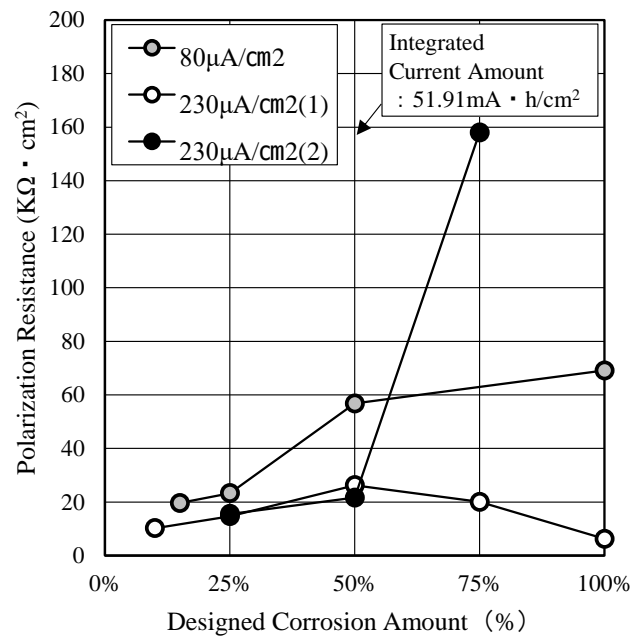

$\mathrm{W} / \mathrm{C} 83.5 \%$

Fig.6 Behavior of $R_{p}$

\section{Remained Coating Thickness on HDZ Bar by EC Test}

Fig.7 indicates remained coating thickness (RCT) on specimen after EC test. In these graphs, RCT of HDZ bar which is sound and not-corroded was indicated as a reference thickness. By means of Equation (2), it was found that measured thickness was $155 \mu \mathrm{m}$. Though there was a $25 \mu \mathrm{m}$ difference in comparison to the result by thickness meter $(180 \mu \mathrm{m}), 155 \mu \mathrm{m}$ was applied because all specimens were evaluated by Equation (2). In $\mathrm{W} / \mathrm{C} 50 \%$, there was an increase of RCT at $25 \%$ of DCA and it started to decrease after $50 \%$ of DCA. On the other hand, in W/C $83.5 \%$, a decrease of RCT was found at $25 \%$ of DCA and it continued until $75 \%$ of DCA. After $75 \%$, there was no noticeable change of thickness. This result was well corresponded with surface change of HDZ bar which was discussed in Fig.5. That is, formation of the oxide film mainly influenced zinc thickness of $\mathrm{HDZ}$ bar in $\mathrm{W} / \mathrm{C} 50 \%$ and active generation of $\mathrm{Zn}(\mathrm{OH})_{2}$ was influential in $\mathrm{W} / \mathrm{C} 83.5 \%$. However, an influence by different AC density was not clearly shown in this experiment. W/C mainly affected its behavior. 

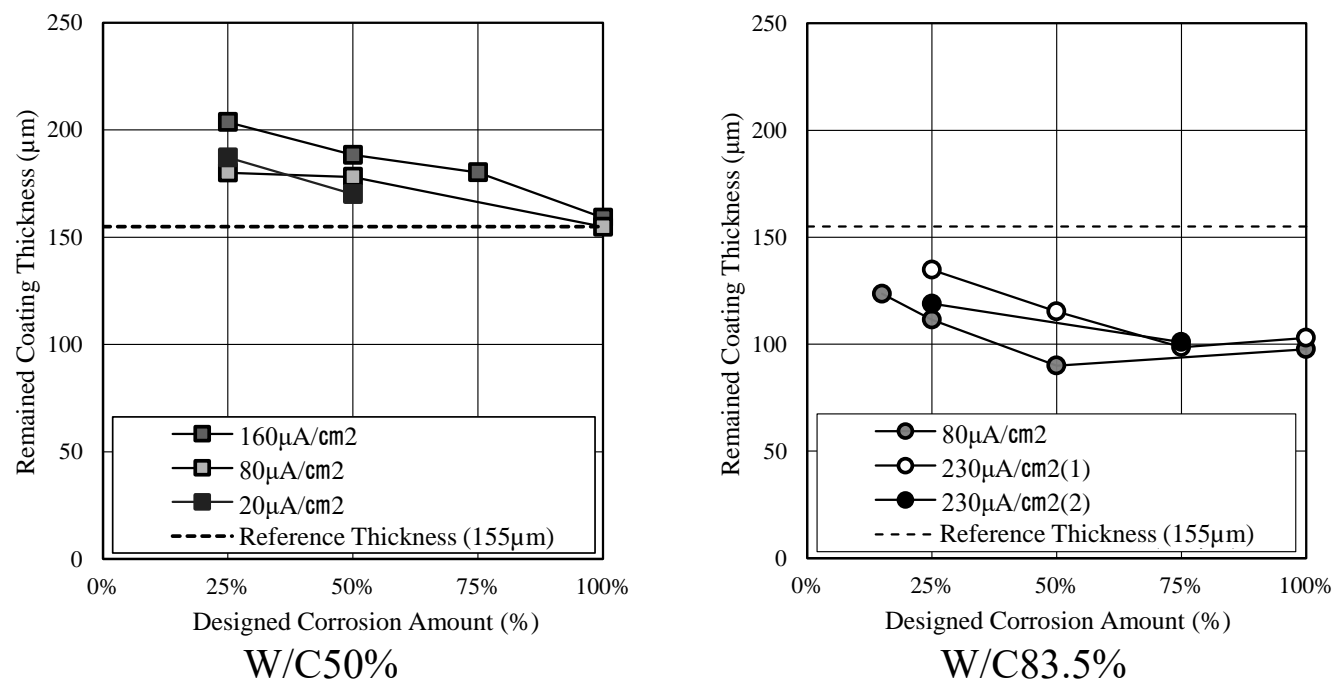

Fig.7 Remained Coating Thickness after EC Test

\section{Property of Oxide Film Formed on Galvanized Rebar}

Fig. 8 indicates thickness change of HDZ bar (in W/C50\%) after EC test in comparison to reference thickness. It was to investigate an influence of oxide film which was formed at $25 \%$ of DCA and resulted in increase of RCT than not-corroded state. In addition, it was to predict actually corroded amount of zinc which was unable to be evaluated in Fig.7. It was because the oxide film was not detachable by metal brush. By that reason, the thickness of oxide film was included in measuring RCT. In this graph, reference thickness was expressed as $0 \mu \mathrm{m}$. As explained in Table 5, thickness change was calculated by Equation (2). $\mathrm{W}_{1}$ is presumed weight of not-corroded HDZ bar by its length. Through measuring randomly chosen 15 samples, average weight per unit length was found as $1.56 \mathrm{~g} / \mathrm{mm} . \mathrm{W}_{2}$ is weight of HDZ bar before elimination of zing coating which corroded by EC test. Thus the calculation is $\left(\mathrm{W}_{1}-\mathrm{W}_{2}\right)$, in interpreting thickness change, $(+)$ indicates decrease and $(-)$ indicates increase.

As a result, approximately $50 \sim 55 \mu \mathrm{m}$ of thickness was increased to the maximum during $25 \sim 75 \%$ of DCA. After $75 \%$, specimens showed noticeable decrease of thickness. This implies that oxide film is formed firstly before active corrosion of zinc is initiated and its predicted maximum thickness is about $52.5 \mu \mathrm{m}$. Therefore, it is assumed that the oxide film maintains a constant thickness once it is fully formed. Though it was covered by zinc product as corrosion progressed, it was found that this oxide film still existed after removal of zinc product. This makes it understandable why RCT in W/C50\% was higher than reference thickness during the specimen's corrosion as shown in Fig.7. From the result that the oxide film was found as well in W/C $83.5 \%$ as shown in Fig.5, it is assumed that the evaluated RCT in W/C $83.5 \%$ would include the thickness of oxide film. Therefore, in this study, in order to predict actual corrosion amount of HDZ bar, $-52.5 \mu \mathrm{m}$ was added from the measured RCT of all specimens and it was discussed in Fig. 10.

Fig.9 indicates XDR analysis of oxide film. It was found that main component was $\mathrm{SiO}_{2}$. Langill and Dugan (2004) stated that $\mathrm{Si}$ is a key component for manufacturing 
HDZ bar to form zinc coating which has stable structure and sufficient thickness. In this experiment which regarded low range of AC density, it was found that not only zinc but also $\mathrm{Si}$, which was included in $\mathrm{HDZ}$ bar, generated anodic reaction. Riordan (2007) stated that $\mathrm{SiO}_{2}$ is known to act as electrical insulator. Therefore, it was clarified that oxide film which was discussed in Fig.5 influenced delaying the corrosion of zinc.

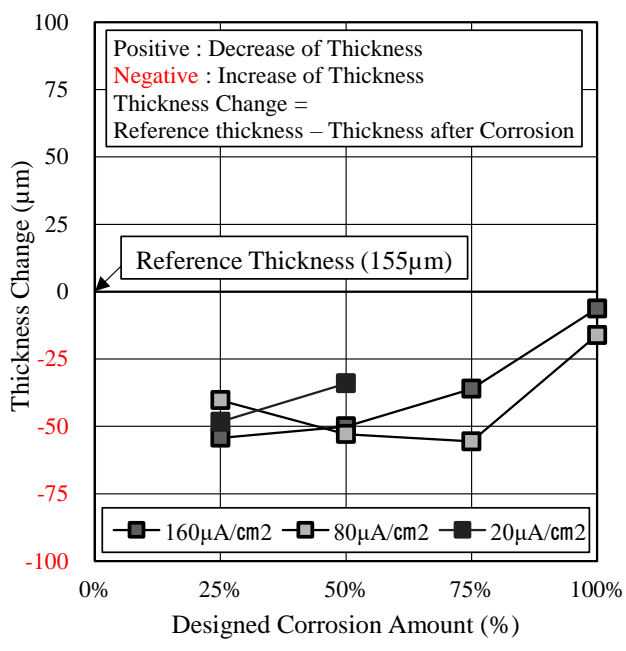

Fig. 8 Presumed Thickness of Oxide Film in W/C $50 \%$

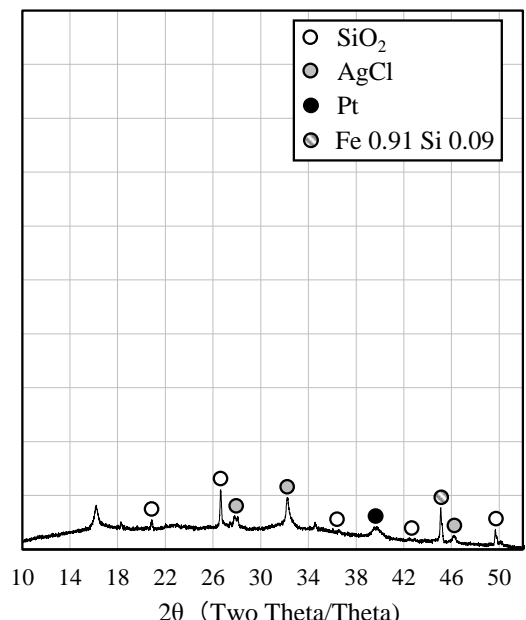

Fig. 9 Property of

Oxide Film by XRD Analysis

\section{Comparison between Actual and Designed Corrosion Amount}

Fig.10 indicates comparison of actual and designed corrosion amount of all specimens. In these graphs, reference thickness was decided as $155 \mu \mathrm{m}$ on both parameters. It was to fit both calculated corrosion amount identically. Accordingly, DCA was adjusted as followed; $25 \% \rightarrow 29 \%, 50 \% \rightarrow 58 \%, 75 \% \rightarrow 87 \%$ and $100 \% \rightarrow 116 \%$. As a result, it was found that the maximum corrosion amount was $29 \%$ in W/C $50 \%$ and approximately $65 \%$ in $\mathrm{W} / \mathrm{C} 83.5 \%$ at $116 \%$ of DCA. Therefore, it was clarified that less than half of integrated corrosion amount by EC test actually influences the corrosion of HDZ bar.

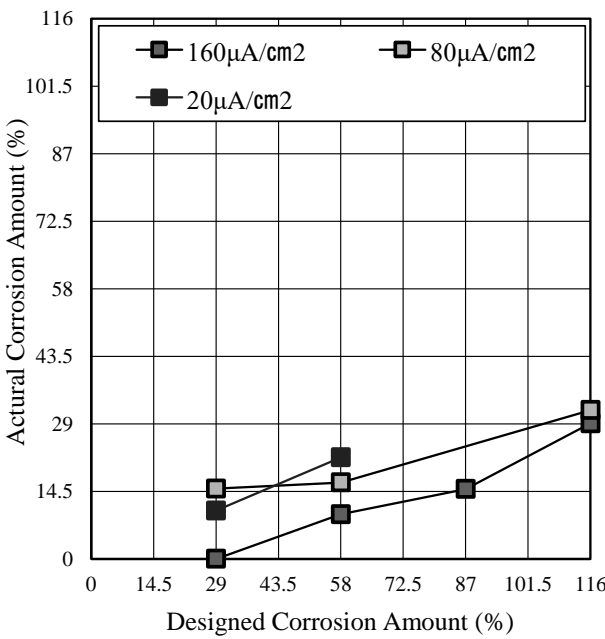

$\mathrm{W} / \mathrm{C} 50 \%$

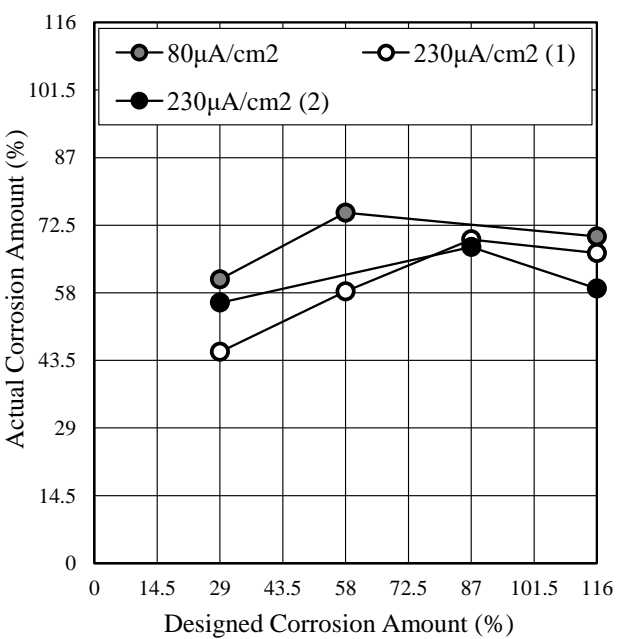

$\mathrm{W} / \mathrm{C} 83.5 \%$

Fig.10 Comparison of Actual and Designed Corrosion Amount 


\section{CONCLUSION}

In this study, investigation on adequate condition of accelerated corrosion test was carried out from simulated electrolytic corrosion by galvanostatic method. It was to evaluate anti-corrosion performance of galvanized rebar. As a test condition, various range of applied current density, which is $20 \sim 230 \mu \mathrm{A} / \mathrm{cm}^{2}$, was tested on galvanized rebar embedded in concrete. In addation, W/C of concrete $(50 \%, 83.5 \%)$ and test period ( $0 \sim 100 \%$ of designed corrosion amount) were considered.

(1) From the observation of surface change by corrosion, it was found that the oxide film protected the zinc coating such as thin layer. It was clearly shown that high W/C of concrete makes galvanized bar easy to be corroded and generates more $\mathrm{Zn}(\mathrm{OH})_{2}$.

(2) Galvanized rebar was found to perform the increase of polarization resistance $\left(R_{p}\right)$ as the applied current density is lower. Furthermore, $R_{p}$ showed the increasing behavior as corrosion has progressed.

(3) From XDR analysis of oxide film, main component was found as $\mathrm{SiO}_{2}$ which is known to act as electrical insulator. In this experiment which regarded low range of applied current density, not only zinc but also $\mathrm{Si}$, which was included in galvanized bar, generated anodic reaction.

(4) Actual corrosion amount was shown smaller than the designed one by performing adequate anti-corrosion behavior. In conclusion, within $160 \mu \mathrm{A} / \mathrm{cm}^{2}$ was assumed to be appropriate in the scope of this study.

\section{REFERENCES}

Choe, H. B., Nishio, Y., and Kanematsu, M. (2018a). "Evaluation of galvanic corrosion between hot dip galvanized steel and ordinary steel rebar in concrete environment." Proc. of the $8^{\text {th }}$ Int. Conf. of Asian Concr. Federation, 731-738.

Choe, H. B., Nishio, Y., and Kanematsu, M. (2018b). "An experimental study on galvanic corrosion of galvanized steel reinforcement in contact with ordinary steel reinforcement (in Japanese)." The $18^{\text {th }}$ JSMS Symp. on Concr. Struct. Scenarios, 18, 19-24.

Niwa, A., Choe, H. B., and Kanematsu, M. (2018). "The Bonding performance of hotdip galvanized steel in the concrete with regard to its corrosion behavior (in Japanese)." Proc. Jpn. Concr. Inst., 40(1), 969-974.

Kouril, M., Pokorny, P., and Stoulil, J. (2017) "Corrosion mechanism and bondstrength study on galvanized steel in concrete environment." Corros. Sci. Tech., 16(2), 69-75

Figueira, R. B., Silva, C. J. R., Pereira, E. V., and Salta, M. M. (2014). "Corrosion of hot-dip galvanized steel reinforcement" Corros. Prot. Mater., 33(3), 51-61.

Sistonen, E. (2009). "Service life of hot-dip galvanised reinforcement bars in carbonated and chloride-contaminated concrete" TKK Struct. Eng. Bldg. Tech. 
Dissertations, Helsinki University of Technology.

Farina, S. B., and Duffo, G. S. (2007). "Corrosion of zinc in simulated carbonated concrete pore solutions" Electrochim. Acta, 52, 5131-5139.

Yeomans, S. R. (2004). "Chapter 1. Galvanized steel in concrete: an overview." Galvanized Steel Reinforcement in Concrete, Elseiver Science, 1-30.

Andrade, C., and Alonso, C. (2004). "Chapter 5. Electrochemical aspects of galvanized reinforcement corrosion." Galvanized Steel Reinforcement in Concrete, Elseiver Science, 111-144.

Takaya, S., Nakamura, S., Yamamoto, T., and Miyagawa, T. (2013). "Influence of steel corrosion products in concrete on crack opening weight loss of corrosion (in Japanese)." J. Jpn. Soc. Civ. Eng., E2, 69(2), 154-165.

ASTM G102-89(2015)e1, Standard practice for calculation of corrosion rates and related information from electrochemical measurements, ASTM International, West Conshohocken, PA.

Poursaee, A. (2010). "Potentiostatic transient technique, a simple approach to estimate the corrosion current density and stern-geary constant of reinforcing steel in concrete." Cem. Concr. Res., 40, 1451-1458.

Badea, G. E., Caraban, A., Sebesan, M., Dzitac, S., Cret, P., and Setel, A. (2010). "Polarization measurements used for corrosion rates determination." $J$. Sustainable Energy, 1(1).

JIS H 0401 : 2013, Test methods for hot dip galvanized coatings (in Japanese).

ISO 1460: 1992, Metallic coatings - hot dip galvanized coatings on ferrous materials - gravimetric determination of the mass per unit area.

Powers, R. W., and Breiter, M. W. (1969). "The anodic dissolution and passivation of zinc in concentrated potassium hydroxide solutions." J. Electrochem. Soc., 116(6), 719-729.

Langill, T. J., and Dugan, B. (2004). "Chapter 4: zinc materials for use in concrete." Galvanized Steel Reinforcement in Concrete, Elseiver science, 95-97.

Riordan, M. (2007). "The Silicon Dioxide Solution: How physicist Jean Hoerni built the bridge from the transistor to the integrated circuit." IEEE Spectrum, Retrieved 11 Feb 2019. 